Available online at http://jurnal.stmikroyal.ac.id/index.php/jurteksi

\title{
IMPLEMENTASI CERTAINTY FACTOR DALAM MENGATASI KETIDAKPASTIAN PADA SISTEM PAKAR DIAGNOSA PENYAKIT KUDA LAUT
}

\author{
Rohmat Indra Borman ${ }^{1^{*}}$, Riduwan Napianto ${ }^{1}$, Putri Nurlandari ${ }^{1}$, Zaenal Abidin ${ }^{1}$ \\ ${ }^{1}$ Fakulas Teknik dan Ilmu Komputer (FTIK), Universitas Teknokrat Indonesia \\ email: "rohmat_indra@teknokrat.ac.id
}

\begin{abstract}
In analyzing information, it is possible for experts to disclose information with uncertain recognition. For example, with the use of consent, the use is large and almost certain. In overcoming uncertainty in the system, experts can use the certainty factor (CF) method. This method can overcome reality with a level of certainty based on facts so that it can explain the confidence of an expert. CF can be applied in an expert system to build a program that can diagnose a set of rules. In this study CF was implemented in an expert system diagnosing seahorse disease. Sea horses have a high trading value, both in living and dead conditions. Therefore, sea horses, including animals that are protected by population. In this study, developing an expert system application that can diagnose seahorse disease can help determine the level of trust of experts and users who use related cases. Based on the test results, it shows that $\mathrm{CF}$ is able to cope well and has a high level of accuracy.
\end{abstract}

Keywords: certainty factor; expert system; seahorses.

\begin{abstract}
Abstrak: Informasi yang dihasilkan dalam diagnosa dimungkinkan menggunakan ungkapan ketidakpastian. Misalkan dengan penggunaan pernyataan mungkin (maybe), kemungkinan besar (probably not), hampir pasti (almost certainty) dan pernyataan tidak pasti lainya. Untuk mengatasi ketidak pastian pada sistem pakar dapat menerapkan pendekatan certainty factor $(\mathrm{CF})$. Metode ini mampu mengatasi ketidakpastian dengan mendefinisikan tingkat kepastian berdasarkan fakta sehingga dapat memaparkan keyakinan seorang pakar. CF dapat diterapkan dalam sistem pakar untuk membangun suatu program yang dapat mendiagnosa berdasarkan suatu set aturan. Pada penelitian ini CF diimplementasikan pada sistem pakar diagnose penyakit kuda laut. Kuda laut memiliki nilai jual perdagangan yang tinggi, baik dalam keadaan hidup maupun mati. Oleh sebab itu kuda laut termasuk hewan yang dilindungi populasinya. Penelitian yang dilakukan menghasilkan sistem pakar yang mampu mendiagnosis serta memberikan solusi untuk penyakit kuda laut dengan menggunakan pendekatan $\mathrm{CF}$ dalam penanganan ketidakpastian. Berdasarkan hasil pengujian menunjukkan $\mathrm{CF}$ mampu mengatasi ketidakpastian dengan baik dan memiliki tingkat akurasi yang tinggi.
\end{abstract}

Kata kunci: certainty factor; sistem pakar; kuda laut 
JURTEKSI (Jurnal Teknologi dan Sistem Informasi)

Vol. VII No. 1, Dec 2020, hlm. 1 - 8

DOI: https://doi.org/10.33330/jurteksi.v7i1.602

Available online at http://jurnal.stmikroyal.ac.id/index.php/jurteksi
ISSN 2407-1811 (Print)

ISSN 2550-0201 (Online)

\section{PENDAHULUAN}

Artificial intelligence atau kecerdasan buatan merupakan bidang computer science yang mengkaji tentang bagaimana membangun sistem yang memiliki kemampuan dapat menyelesaikan pekerjaan seperti halnya yang dilakukan oleh manusia. Bagian dari kecerdasan buatan salah satunya yaitu expert system (sistem pakar). Sistem pakar merupakan sistem yang mengadopsi pengetahuan ahli atau pakar pada bidang tertentu ke dalam komputer, sehingga komputer mampu menyelesaikan permasalahan yang biasanya diselesaikan oleh pakar [1]. Dalam sistem pakar melibatkan pengetahuan, fakta, serta cara berpikir dalam penyelesaian permasalahan yang biasanya diselesaikan oleh ahli dalam bidangnya. Pada proses diagnosis seorang pakar akan dihadapkan dengan permasalahan dalam menentukan jawaban, karena akan terdapat jawaban yang belum pasti berupa pernyataan "mungkin", "kemungkinan" besar dan "hampir pasti". Untuk menyelesaikan permasalahan ketidakpasitan dapat menggunakan pendekatan certainty factor (CF). CF merupakan pendekatan yang mendiskripsikan ukuran kepastian berdasarkan fakta sehingga dapat memberikan gambaran tingkat keyakinan seorang pakar [2]. CF memiliki kelebihan dapat memberikan hasil perhitungan berdasarkan tingkat keyakinan dari gejala yang dialami pengguna, sehingga dapat menghasilkan jawaban untuk kasus ketidakpastian sehingga menghasilkan kebenaran yang lebih akurat [3]. Sehingga CF mampu mengukur suatu kejadian (fakta atau masalah) dalam ketidakpastian. Pada CF aturan dan kaidah yang ditetapkan memiliki nilai tingkat keyakinan sendiri selain hipotesanya yang terdapat nilai tingkat keyakinan [4].

CF dapat diterapkan dalam sistem pakar untuk membangun suatu aplikasi berdasarkan aturan, untuk menghasilkan analisis informasi mengenai permasalahan yang spesifik serta menghasilkan analisis secara matematis dari permasalahan yang diselesaikan. Pada beberapa penelitian sebelumnya CF mampu memberikan hasil yang baik dalam mengatasi ketidakpastian dengan tingkat akurasi yang tinggi [5]-[8]. Pada penelitian ini $\mathrm{CF}$ akan diterapkan untuk menyelesaikan masalah berupa diagnosa penyakit pada hewan kuda laut. Kuda laut (Hippocampus spp) merupakan jenis ikan hias yang memiliki nilai komersil, unik dan potensil untuk dibudidayakan, karena dapat memijah secara alami sepanjang tahun dan tidak bersifat kanibal. Kuda laut dapat berenang secara tegak, naik turun atau maju perlahanlahan dalam air, sehingga ini menjadi keunikan tersendiri untuk binatang ini. Kuda laut memiliki nilai jual perdagangan yang tinggi, baik dalam keadaan hidup maupun mati. Namun. kuda laut termasuk kategori binatang yang terancam populasinya di alam, hal ini disebabkan telah terjadi eksploitasi terhadap kuda laut [9]. Oleh sebab itu, kuda laut termasuk hewan yang dilindungi populasinya. Dalam mengurangi dampak dari penangkapan bebas salah satunya dengan kegiatan budidaya. Permasalahan utama yang di hadapi dalam pembudidayaan kuda laut adalah masalah penyakit yang dapat mengakibatkan kematian masal dan berkurangnya hasil panen. Untuk itu penelitian ini akan mengem-bangkan sistem pakar yang dapat membantu diagnosa penyakit kuda laut dengan menerapkan algoritm certainty factor (CF) dalam mengatasi ketidakpastian. 
JURTEKSI (Jurnal Teknologi dan Sistem Informasi)

Vol. VII No. 1, Dec 2020, hlm. 1 - 8

DOI: https://doi.org/10.33330/jurteksi.v7i1.602

Available online at http://jurnal.stmikroyal.ac.id/index.php/jurteksi
ISSN 2407-1811 (Print)

ISSN 2550-0201 (Online)

\section{METODE}

Dalam penanganan ketidakpastian pada penelitian ini menggunakan pendekatan certainty factor (CF). Konsep certainty factor (CF) dikemukakan pertama kali oleh Shortlife dan Buchanan pada 1975 dalam pembuatan MYCIN guna menyelesaikan permasalahan ketidakpastian pemikiran seorang pakar. MYCIN merupakan sistem pakar untuk diagnosa penyakit pada infeksi pada darah. MYCIN sistem yang berbasis aturan yang dapat mengenali sekitar 100 penyebab infeksi bakteri. Metode pemrosesan dan tidak kepastian ini merupakan perintis dan menghasilkan pengaruh jangka panjang dalam pengembangan sistem pakar. Metode CF merupakan pendekatan yang digunakan untuk justifikasi suatu fakta itu pasti ataukah tidak pasti [10]. Certainty factor diinterprestrasikan dalam persamaan (1) berikut [11]:

$$
\begin{aligned}
& \mathrm{CF}[\mathrm{H} . \mathrm{E}]=\mathrm{MB}[\mathrm{H} . \mathrm{E}]-\mathrm{MD}[\mathrm{H} . \mathrm{E}] \\
& \mathrm{CF}_{\text {gejala }}=\mathrm{CF}_{[\text {user }]} * \mathrm{CF}_{[\text {pakar }]}
\end{aligned}
$$

Keterangan

$\mathrm{CF}=$ Faktor kepastian dari hipotesa $\mathrm{H}$ yang dipengaruhi gejala $\mathrm{E}$.

$\mathrm{MB}=$ Measure of Belief (tingkat kepercayaan), merupakan ukuran kenaikan kepercayaan hipotesa $\mathrm{H}$ dipengaruhi oleh gejala E.

$\mathrm{MD}=$ Measure of Disbelief (tingkat ketidak percayaan), merupakan kenaikan ketidakpercayaan hipotesa $\mathrm{H}$ terhadap gejala E.

Dalam menentukan tingkat kepercayaan atau keyakinan dari pakar, maka dapat dihitung dengan CFcombine dengan dasar tabel aturan nilai kepercayaan [12], dapat dilihat pada tabel 1 berikut.

Tabel 1. Aturan Nilai kepercayaan

\begin{tabular}{cc}
\hline Uncertain Term & CF \\
\hline Definitely not (Pasti tidak) & $-1,0$ \\
\hline $\begin{array}{c}\text { Almost certainly not } \\
\text { (Hampir pasti tidak) }\end{array}$ & $-0,8$ \\
\hline $\begin{array}{c}\text { Probably not } \\
\text { (Kemungkinan besar } \\
\text { tidak) }\end{array}$ & $-0,6$ \\
\hline $\begin{array}{c}\text { Maybe not (Mungkin } \\
\text { tidak) }\end{array}$ & $-0,4$ \\
\hline $\begin{array}{c}\text { Unknown (Tidak tahu) } \\
\text { Maybe (Mungkin) }\end{array}$ & $-0,2$ \\
\hline $\begin{array}{c}\text { Probably (Kemungkinan } \\
\text { besar) }\end{array}$ & 0,2 \\
\hline $\begin{array}{c}\text { Almost certaintly (Hampir } \\
\text { pasti) }\end{array}$ & 0,6 \\
\hline Definitely (Pasti) & 0,8 \\
\hline \multicolumn{1}{c}{ (Hom }
\end{tabular}

Untuk mendiagnosa penyakit, user atau pengguna aplikasi disajikan pada pilihan tingkat keyakinan masingmasing pengguna berdasarkan dari fakta atau gejala yang dihadapi. Jika terdapat kasus memiliki banyak gejala, maka $\mathrm{CF}$ dapat diselesaikan dengan persamaan (2) berikut:

$\mathrm{CF}_{\text {combine }}=\mathrm{CF}_{1}+\mathrm{CF}_{2} *\left(1-\mathrm{CF}_{1}\right)$

Dimana $\mathrm{CF}_{1}$ dan $\mathrm{CF}_{2}$ memiliki hipotesis yang sama:

$\mathrm{CF}_{1}=$ nilai certainty factor evidence 1 terhadap hipotesis

$\mathrm{CF}_{2}=$ nilai certainty factor evidence 2 terhadap hipotesis

Selanjutnya hasil dari $\mathrm{CF}_{\text {combine }}$ yang pertama akan menjadi $\mathrm{CF}_{\text {old. }}$.

\section{HASIL DAN PEMBAHASAN}

Tahap awal pada pengembangan sistem pakar dilakukan akuisisi pengetahuan untuk mendapatkan data yang dibutuhkan seperti data gejala, penyakit, solusi serta nilai keyakinan 
JURTEKSI (Jurnal Teknologi dan Sistem Informasi)

Vol. VII No. 1, Dec 2020, hlm. 1 - 8

DOI: https://doi.org/10.33330/jurteksi.v7i1.602

Available online at http://jurnal.stmikroyal.ac.id/index.php/jurteksi

setiap gejala dan penyakit dari pakar. Data didapatkan berdasarkan interview dengan ahli atau pakar yang ada di BBPBL (Balai Besar Pengembangan Budidaya Laut) Provinsi Lampung. Berikut ini data gejala, penyakit serta tingkat keyakinan dari pakar.

Tabel 2. Data penyakit Bakteri Vibrio

No Serangan gejala yang Bobot
terjadi

\begin{tabular}{lll}
\hline 1. & Punggung kehitam-hitaman & 0,6 \\
\hline 2. & Bercak merah pada pangkal & 0,4
\end{tabular}
sirip

\begin{tabular}{lll}
\hline 3. & Bergerak lamban & 0,8 \\
\hline 4. & Keseimbangan terganggu & 0,4
\end{tabular}

5. Nafsu makan berkurang 0,6

6. Perut kembung 1,0

\begin{tabular}{lll} 
7. & Mata menonjol & 0,4 \\
\hline 8. & Pendarahan pada insang & 0,6 \\
\hline
\end{tabular}

Tabel 3. Data Penyakit Aeromenas

\begin{tabular}{clc}
\hline No & $\begin{array}{c}\text { Serangan gejala yang } \\
\text { terjadi }\end{array}$ & Bobot \\
\hline 1. & Menjadi penyendiri & 0,8 \\
\hline 2. & Tubuh terlihat lemah & 1,0 \\
\hline 3. & Nafsu makan berkurang & 0,4 \\
\hline 4. & Kulit mengelupas & 0,8 \\
\hline 5. & Produksi lendir berlebih & 0,6 \\
\hline 6. & Tubuh terlihat kurus & 0,4 \\
\hline 7. & $\begin{array}{l}\text { Bercak putih di ujung } \\
\text { ekor }\end{array}$ & 0,8 \\
\hline
\end{tabular}

Tabel 4. Data penyakit Parasit Nemotoda No Serangan gejala yang Bobot terjadi

\begin{tabular}{cll}
\hline 1. & Nafsu makan berkurang & 0,4 \\
\hline 2. & Terjadi implamasi & 0,8 \\
\hline 3. & Terjadi hemoragik & 0,4 \\
\hline 4. & Pembengkakan di perut & 0,6 \\
\hline 5. & Produksi lendir berlebih & 1,0 \\
\hline
\end{tabular}

Tabel 5. Data prnyakit Protozoa

\begin{tabular}{clc}
\hline No & \multicolumn{1}{c}{$\begin{array}{l}\text { Serangan gejala yang } \\
\text { terjadi }\end{array}$} & Bobot \\
\hline 1. & $\begin{array}{l}\text { Sering menggosokan } \\
\text { tubuh ke karang atau } \\
\text { lantai bak }\end{array}$ & 0,4 \\
\hline 2. & $\begin{array}{l}\text { Sering menggoyang- } \\
\text { goyangkan tubuh }\end{array}$ & 0,6 \\
\hline 3. & $\begin{array}{l}\text { Terdapat rambut halus } \\
\text { yang menempel ditubuh } \\
\text { atau ekor }\end{array}$ & 0,8 \\
\hline 4. & Ekor terputus & 0,4 \\
\hline 5. & $\begin{array}{l}\text { Tergeletak didasar dan } \\
\text { tidak dapat berenang }\end{array}$ & 0,6 \\
\hline
\end{tabular}

Proses perhitungan presentasi dimulai dari keyakinan dengan kaidah (rule) berdasarkan fakta atau gejala, menjadi aturan yang memiliki gejala tunggal. Selanjutnya setiap aturan baru dihitung nilai faktor kepastian, jika gejala dari penyakit yang akan di diagnosa memiliki banyak gejala, maka faktor kepastian dari penyakit tersebut dihitung dengan persamaan (3) berikut :

$$
\mathrm{CF}_{\text {combine }}=\mathrm{CF}_{\text {old }}+\mathrm{CF}_{\text {gejala }} *\left(1-\mathrm{CF}_{\text {old }}\right)
$$

Berikut ini studi kasus dalam penerapan certainty factor. Misalkan terdapat aturan atau kaidah sebagai berikut :

IF Keseimbangan terganggu

AND Ekor melengkung kebelakang tubuh

AND Berenang dengan posisi

kepala dibawah

AND Banyak gelembung

dibawah kulit ekor

AND Tubuh mengapung dan

tidak bisa tenggelam

AND Terdapat udara pada

kantung pengeraman

THEN Penyakit Buble Desease 
DOI: https://doi.org/10.33330/jurteksi.v7i1.602

Available online at http://jurnal.stmikroyal.ac.id/index.php/jurteksi

\begin{tabular}{lr}
\multicolumn{2}{c}{ Langkah } \\
menentukan nilai & pertam \\
masing-masing gejala berpet \\
tabel penyakit Buble
\end{tabular}

Pengguna menentukan tingkat kepercayaan terhadap gejala dengan nilai berikut :

Gejala $1=0,8$ (Hampir Pasti)

Gejala $2=1,0$ (Pasti)

Gejala $3=0,6$ (Kemungkinan Besar)

Gejala $4=0,4$ (Mungkin)

Gejala $5=0,6$ (Kemungkinan Besar)

Gejala $6=1,0$ (Pasti)

Kaidah pertama memiliki 6 (enam) gejala yang kemudian dibagi menjadi beberapa aturan, sehingga menjadi:

Aturan 1

IF Keseimbangan terganggu THEN Penyakit Buble Desease

Aturan 2

IF Ekor melengkung kebelakang tubuh THEN Penyakit Buble Desease

Aturan 3

IF Berenang dengan posisi kepala dibawah THEN Penyakit Buble Desease Aturan 4

IF Banyak gelembung dibawah kulit ekor THEN Penyakit Buble Desease

Aturan 5

IF Tubuh mengapung dan tidak bisa tenggelam THEN Penyakit Buble

Desease

Aturan 6

IF Terdapat udara pada kantung pengeraman THEN Penyakit Buble

\section{Desease}

Proses perhitungan aturan 1 :

$$
\begin{aligned}
\mathrm{CF}_{\text {gejala } 1} & =\mathrm{CF}_{\text {[user] }} * \mathrm{CF}_{\text {[pakar] }} \\
& =0,8 * 1,0 \\
& =0,8
\end{aligned}
$$

Proses perhitungan aturan 2 :

$$
\begin{aligned}
\mathrm{CF}_{\text {gejala 2 }} & =\mathrm{CF}_{\text {[user] }} * \mathrm{CF}_{\text {[pakar] }} \\
& =1,0 * 0,6 \\
& =0,6
\end{aligned}
$$

Proses perhitungan aturan 3 :

$$
\begin{aligned}
\mathrm{CF}_{\text {gejala } 3} & =\mathrm{CF}_{\text {[user] }} * \mathrm{CF}_{\text {[pakar] }} \\
& =0,6 * 0,8 \\
& =0,48
\end{aligned}
$$

Proses perhitungan aturan 4 :

$$
\begin{aligned}
\mathrm{CF}_{\text {gejala } 4} & =\mathrm{CF}_{\text {[user] }} * \mathrm{CF}_{\text {[pakar] }} \\
& =0,4 * 1,0 \\
& =0,4
\end{aligned}
$$

Proses perhitungan aturan 5 :

$$
\begin{aligned}
\mathrm{CF}_{\text {gejala } 5} & =\mathrm{CF}_{\text {[user] }} * \mathrm{CF}_{\text {[pakar] }} \\
& =0,6 * 0,4 \\
& =0,24
\end{aligned}
$$

Proses perhitungan aturan 6 :

$$
\begin{aligned}
\mathrm{CF}_{\text {gejala } 6} & =\mathrm{CF}_{\text {[user] }} * \mathrm{CF}_{\text {[pakar] }} \\
& =1,0 * 0,4 \\
& =0,4
\end{aligned}
$$

Pada studi kasus ini penyakit memiliki banyak gejala, sehingga dalam mendapatkan nilai $\mathrm{CF}$ menggunakan perhitungan berikut ini:

$$
\begin{aligned}
& \mathrm{CF}_{\text {combine 1 }}\left(\mathrm{CF}_{\text {gejala 1 }}, \mathrm{CF}_{\text {gejala 2 }}\right) \\
& \mathrm{CF}_{\text {gejala 1 }}+\mathrm{CF}_{\text {gejala 2 } 2} *\left(1-\mathrm{CF}_{\text {gejala 1 }}\right)= \\
& 0,8+0,6 *(1-0,8)=0,8+0,12= \\
& 0,92\left(\mathrm{CF}_{\text {old } 1}\right)
\end{aligned}
$$

$\mathrm{CF}_{\text {combine } 2}\left(\mathrm{CF}_{\text {old 1 1 }}, \mathrm{CF}_{\text {gejala 3 }}\right)=$

$\mathrm{CF}_{\text {old } 1}+\mathrm{CF}_{\text {gejala } 3} *\left(1-\mathrm{CF}_{\text {old } 1}\right)=$

$0,92+0,48 *(1-0,92)=$

$0,92+0,0384$

$0,9584\left(\mathrm{CF}_{\text {old } 2}\right)$

$\begin{array}{ll}\mathrm{CF}_{\text {combine 3 }}\left(\mathrm{CF}_{\text {old 2 }}, \mathrm{CF}_{\text {gejala } 4}\right) & = \\ \mathrm{CF}_{\text {old 2 }}+\mathrm{CF}_{\text {gejala } 4} *\left(1-\mathrm{CF}_{\text {old 3 }}\right) & = \\ 0,9584+0,4 *(1-0,9584) & =\end{array}$ 
JURTEKSI (Jurnal Teknologi dan Sistem Informasi)

Vol. VII No. 1, Dec 2020, hlm. 1 - 8

DOI: https://doi.org/10.33330/jurteksi.v7i1.602

Available online at http://jurnal.stmikroyal.ac.id/index.php/jurteksi

\section{$0,9584+0,01664$}

$0,97504\left(\mathrm{CF}_{\text {old } 3}\right)$

$\mathrm{CF}_{\text {combine } 4}\left(\mathrm{CF}_{\text {old } 3}, \mathrm{CF}_{\text {gejala } 5}\right)$

$\mathrm{CF}_{\text {old } 3}+\mathrm{CF}_{\text {gejala } 5} *\left(1-\mathrm{CF}_{\text {old } 3}\right)$

$0,97504+0,24 *(1-0,97504)$

$0,97504+0,0059904$

$0,9810304\left(\mathrm{CF}_{\text {old } 4}\right)$

$\mathrm{CF}_{\text {combine } 5}\left(\mathrm{CF}_{\text {old } 4}, \mathrm{CF}_{\text {gejala } 6}\right)$

$\mathrm{CF}_{\text {old } 4}+\mathrm{CF}_{\text {gejala } 6} *\left(1-\mathrm{CF}_{\text {old }} 4\right)$

$0,9810304+0,4 *(1-0,9810304)$

$0,9810304+0,00758784$

$0,9886124\left(\mathrm{CF}_{\text {old }} 5\right)$

$\mathrm{CF}_{\text {old }}$ terakhir merupakan $\mathrm{CF}_{\text {penyakit, berdasarkan hasil perhitungan }}$ menghasilkan nilai 0,9886124 atau $98.86 \%$. Jadi berdasarkan studi kasus diatas didapati hasil dari diagnosa adalah 98.86\% terserang penyakit Buble Desease.

Selanjutnya dalam penelitian ini dilakukan tahapan implementasi. Pada tahapan ini dilakukan pembuatan program dengan bahasa pemrogram tertentu untuk kemudian menjadi sebuah aplikasi [13]. Aplikasi sistem pakar diagnosa penyakit kuda laut ini dikembangkan dengan berbasis website dengan pengkodean menggunakan bahasa pemrograman PHP dengan tools text editor Sublime Text dan database MySql. Terdapat dua pengguna pada aplikasi ini, yaitu : user (pengguna umum), admin (BBPBL Provinsi Lampung). Untuk mempermudah akses user atau pembudidaya yang akan mendiagnosa penyakit kuda laut tidak perlu login dan dapat langsung menggunakan sistem.
ISSN 2407-1811 (Print)

ISSN 2550-0201 (Online) 
JURTEKSI (Jurnal Teknologi dan Sistem Informasi)

Vol. VII No. 1, Dec 2020, hlm. 1 - 8

DOI: https://doi.org/10.33330/jurteksi.v7i1.602

Available online at http://jurnal.stmikroyal.ac.id/index.php/jurteksi

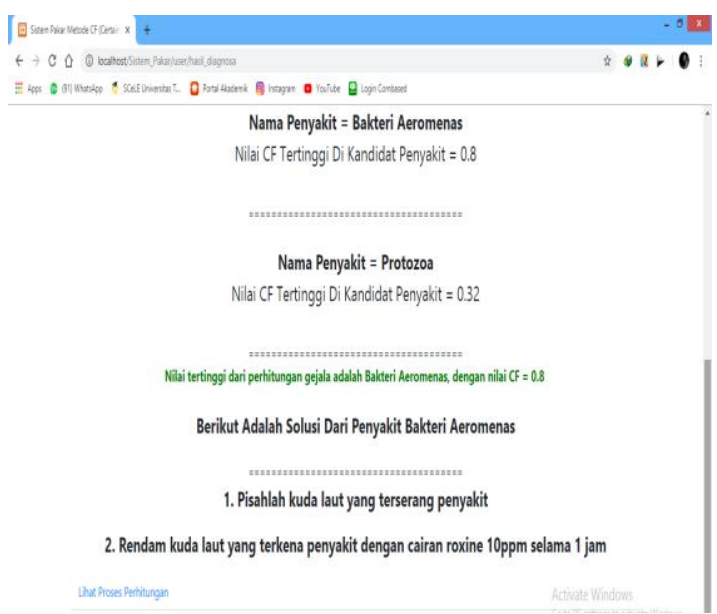

Gambar 3. Tampilan Hasil Diagnosa

Sedangkan untuk admin dapat melakukan login admin kedalam sistem, kemudian dapat mengelola gejala, penyakit, aturan pakar dan bobot tingkat keyakinan serta solusi penanganan penyakit.

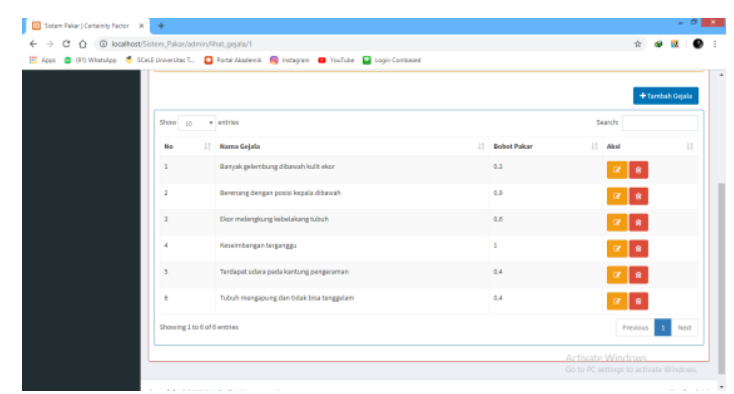

Gambar 5. Tampilan Mengelola Penyakit

Setelah CF diimplementasikan dalam aplikasi, selanjutnya dilakukan pengujian untuk mengetahui tingkat akurasi metode CF. Uji akurasi dilaksanakan dengan mencocokkan diagnosa analisa pakar dengan apa yang dihasilkan oleh sistem [14]. Untuk uji akurasi, penelitian ini menggunakan 15 kasus secara random kepada sistem pakar dan pakar penyakit kuda laut, kemudian hasilnya akan dibandingkan. Dari 15 kasus yang telah diujicobakan sistem pakar mampu menjawab secara valid seabanyak 13 kasus atau 86,6\%. Hasil

tersebut tergolong pada kriteria baik, dengan klasifikasi persentase sebagaia berikut : Baik, dengan nilai 76\%-100\%; Cukup, dengan nilai 56\%-75\%; Kurang Baik, dengan nilai 40\%-55\%, sedangkan Tidak Baik, memiliki nilai kurang dari $40 \%$ [15]. Hal ini menunjukkan bahwa sistem pakar diagnose penyakit kuda laut dengan menerapkan metode $\mathrm{CF}$ mampu berfungsi dengan baik.

\section{SIMPULAN}

Penelitian ini menghasilkan aplikasi diagnosa penyakit kuda laut yang dapat mendiagnosa berdasarkan gejala yang dipilih oleh pengguna kemudian menghasilkan penyakit dan solusi dengan metode certainty factor (CF). CF mampu mengatasi ketidakpastian dengan memberikan nilai tingkat keyakinan dari pakar dan pengguna. Berdasarkan hasil pengujian akurasi $\mathrm{CF}$ mampu menghasilkan tingkat akurasi $86,6 \%$, hal ini menunjukan sistem dapat berfungsi dengan baik dalam mendiagnosa.

\section{DAFTAR PUSTAKA}

[1] H. Liana and C. Lubis, "Sistem Pakar Diagnosis Kerusakan Komputer Dan," J. Ilmu Komput. dan Sist. Inf., vol. 6, no. 2, pp. 9294, 2018.

[2] A. Sucipto, Y. Fernando, R. I. Borman, and N. Mahmuda, "Penerapan Metode Certainty Factor Pada Diagnosa Penyakit Saraf Tulang Belakang," J. Ilm. FIFO, vol. 10, no. 2, p. 18, 2019, doi: 10.22441/fifo.2018.v10i2.002.

[3] A. Riadi, "Penerapan Metode Certainty Factor Untuk Sistem Pakar Diagnosa Penyakit Diabetes 
Available online at http://jurnal.stmikroyal.ac.id/index.php/jurteksi

Melitus Pada RSUD Numi Panua Kabupaten Pohuwato," Ilk. J. Ilm., vol. 9, no. 3, pp. 309-316, 2017.

[4] A. Anita, S. Ningsih, and D. Solin, "Penerapan Metode Forward Chaining dan Certainty Factor Untuk Diagnosa Penyakit Tanaman Bonsai," JGK (Jurnal Guru Kita), vol. 3, no. 2, pp. 187194, 2019.

[5] R. Hariyanto and K. Sa'diyah, "Sistem Pakar Diagnosis Penyakit dan Hama Pada Tanaman Tebu Menggunakan Metode Certainty Factor," J. Inf. Technol. Comput. Sci., vol. 3, no. 1, pp. 1-4, 2018, doi: $10.31328 /$ jo.

[6] D. T. Yuwono, A. Fadlil, and S. Sunardi, "Penerapan Metode Forward Chaining dan Certainty Factor Pada Sistem Pakar Daignosa Hama Anggrek Coelogyne Pandurata," Kumpul. J. lти Komput., vol. 04, no. 02, pp. 136-145, 2017.

[7] K. E. Setyaputri, A. Fadlil, and S. Sunardi, "Analisis Metode Certainty Factor pada Sistem Pakar Diagnosa Penyakit THT," J. Tek. Elektro, vol. 10, no. 1, pp. 30-35, 2018, doi: 10.15294/jte.v10i1.14031.

[8] H. Sulistiani and K. Muludi, "Penerapan Metode Certainty Factor Dalam Mendeteksi Penyakit Tanaman Karet," $J$. Pendidik. Teknol. dan Kejuru., vol. 15, no. 1, pp. 51-59, 2018, doi: $10.23887 /$ jptkundiksha.v15i1.13021.

[9] S. Nizam, "Menelisik Aspek-aspek yang Mempengaruhi Populasi Kuda Laut," Batamnews, 2019. .

[10] S. R. Wicaksono, Studi Kasus Sistem Berbasis Pengetahuan. Malang: Seribu Bintang, 2018.
[11] K. Kusrini, Aplikasi Sistem Pakar Menentukan Faktor Kepastian Pengguna Dengan Metode Kuantifikasi Pernyataan. Yogyakarta: Andi Offset, 2008.

[12] N. A. Putri, "Sistem Pakar untuk Mengidentifikasi Kepribadian Siswa Menggunakan Metode Certainty Factor dalam Mendukung Pendekatan Guru," INTECOMS J. Inf. Technol. Comput. Sci., vol. 1, no. 1, pp. 7890, 2018, doi: 10.31539/intecoms.v1i1.164.

[13] R. I. Borman and H. Fauzi, "Penerapan Metode Perbandingan Eksponensial (MPE) Dalam Sistem Pendukung Keputusan Penerimaan Beasiswa Siswa Berprestasi Pada SMK XYZ," CESS J. Comput. Eng. Syst. Sci., vol. 3, no. 1, pp. 17-22, 2018.

[14] R. I. Borman, D. A. Megawaty, and A. Attohiroh, "Implementasi Metode TOPSIS Pada Sistem Pendukung Keputusan Pemilihan Biji Kopi Robusta Yang Bernilai Mutu Ekspor ( Studi Kasus : PT . Indo Cafco Fajar Bulan Lampung )," Fountain Informatics J., vol. 5, no. 1, pp. 14-20, 2020, doi: 10.21111/fij.v5i1.3828.

[15] M. H. Sayogo, "Penerapan Model Problem Based Learning Dalam Proses Pembelajaran Standar Kompetensi Mengukur Dengan Alat Ukur Mekanik Presisi Di Kelas X Smk Negeri Kudu Jombang," J. Pendidik. Tek. Mesin UNESA, vol. 5, no. 02, pp. 84-90, 2016. 